\title{
Analyzing the Content of Reading Texts Questions in Flying High for Saudi Arabia
}

\author{
Majed Barashid ${ }^{1}$ \\ ${ }^{1}$ Technical College, Technical College of Al-jouf, Aljouf, Saudi Arabia \\ Correspondence: Majed Barashid, Technical College, Technical College of Al-jouf, Aljouf, Saudi Arabia. E-mail: \\ majedbarashid@hotmail.com
}

Received: January 12, 2020

Accepted: February 20, 2020

Online Published: May 27, 2020

doi:10.5539/ies.v13n6p96

URL: https://doi.org/10.5539/ies.v13n6p96

\begin{abstract}
This study aimed at analyzing the cognitive levels of the wh-questions following the reading texts in the Students' Book of Flying High for Saudi Arabia One. A Checklist based on the revised cognitive domain of Bloom's Taxonomy was the instrument used to categorize the cognitive levels of these questions and to determine to what extent they are included properly in the Student's Book of Flying High for Saudi Arabia One. The main findings revealed that the wh-questions following the reading texts which are included in the textbook under analysis were not properly included. Also, the authors of the textbook overemphasized the lower thinking skills and neglected higher thinking skills. Such study is recommended to shed light upon the role of the other series of Flying High for Saudi Arabia in developing cognitive skills among secondary Saudi students.
\end{abstract}

Keywords: content analysis, revised bloom's taxonomy, wh-questions, EFL textbook

\section{Introduction}

The most recent EFL curricula have changed the role of EFL teachers from a person who only conveys information to EFL students to that of a facilitator who provides chances for EFL learners to learn the target language in a more challenging style. At the same time, EFL curricula have changed the role of students as well. They changed them from passive learners to active ones who are able to comprehend, apply, analyze, evaluate, and create while learning the language.

Since EFL textbooks play a vital role in teaching and learning the English language in Saudi Arabian schools for both public and private schools, Macmillan Education worked in partnership with the Ministry of Education of Saudi Arabia to develop the course Flying High for Saudi Arabia for use in Grades 10-12 in government schools in KSA. Flying High puts communication first and last and is based on the Triple-A approach to language learning as stated in the teacher's book (Brewster, Davis, \& Rogers; 2013).

Access: Learners are exposed to language in clear, interesting contexts that are relevant to their interests and needs. Analysis: Learners focus on the meanings, forms, and use of language.

Activation: Learners are continuously given opportunities to use language and skills through a wide variety of motivating tasks and text types.

Therefore, it is essential to analyze one of these series which is Flying High for Saudi Arabia One to assess its contribution to the educational system in Saudi Arabia and students' creative thinking skills

The Rand Reading Group (2002, p. 11) defines reading comprehension as "the process of simultaneously extracting and constructing meaning through interaction and involvement with written language". Reading comprehension is the core of the teaching/learning process in all fields. Therefore, EFL textbooks should emphasize reading comprehension strategies and encourage learners to read critically while in language classes (Assaly \& Smadi, 2015). Sidek (2010, p. 83) also, states that EFL textbooks would not be prepared for higher cognitive demands of reading tasks if they only undergo reading texts that require lower cognitive demand.

According to Torrance's (1962) study which was carried out on creative thinking, the thinking process that is operated by students is essential for mental health, high achievements, and professional success in life. Also, Marksberry (1963) remarks that the curriculum should not only provide students with knowledge but also with higher thinking skills and correct their ways of thinking. It is true that teachers teach students knowledge, but 
together with the knowledge that they obtain teachers must also teach their students how to think. This is can be done by utilizing all levels of questions in the cognitive domain described in Bloom's taxonomy.

The current study utilizes the framework of the revised Bloom's taxonomy to analyze the wh-questions following the reading texts in the textbook Flying High for Saudi Arabia One. Bloom, Englehart, Furst, Hill, and Krathwohl (1956) offered six levels for examining the fulfillment of the goals of learners' cognitive domain. These categories were Knowledge, Comprehension, Application, Analysis, Synthesis, and Evaluation. These categories were ordered from simple to complex and from concrete to abstract. The idea of Bloom's taxonomy was revised by Anderson et al. (2001). The lowest level of the original taxonomy, knowledge was renamed and became remembering. Finally, comprehension and synthesis were retitled to understanding and creating respectively.

It is necessary to analyze the questions in EFL textbooks to judge them in the educational frame and to develop learners' thinking skills in particular. Berelson (1952) and Krippendorff (1980) defined content analysis as a systematic, replicable technique for compressing many words of text into fewer content categories based on explicit rules of coding. It allows inferences to be made which can then be corroborated using other methods of data collection (Krippendorff, 1980). Analysis of questions is also essential that allows us to find out the strong and weak points of questions, and to what extent they contribute to developing students' thinking. The content analysis offers us the possibility of choosing which questions should be as they are, or modified. It also incorporates the level of the EFL textbooks whether or not motivate EFL learners towards high thinking skills such as analyzing, evaluating, and creating.

\subsection{Purpose of the Research}

This research aims to find out the extent to which the cognitive levels of the WH-questions following the reading texts of the understudy textbook are properly included.

\subsection{Question of the Study}

This study seeks to answer the following question

To what extent are the wh-questions following the reading texts in the Student's Book of Flying High for Saudi Arabia One properly included?

\subsection{Significance of the Research}

This research analyzes the content of the Reading Texts Questions in Flying High for Saudi Arabia. Besides, it enables Saudi TEFL teachers to look thoroughly into the textbook understudy and know which levels of wh-questions of the reading texts are emphasized.

The findings of this paper can be beneficial and significant for scholars in the field of content analysis of EFL textbooks. Also, they might be more beneficial to textbook writers who may consider the recommendations when designing new EFL curricula, especially for Saudi secondary students.

\subsection{Content under Analysis}

The content under analysis in this study is the wh-questions following the reading texts in the Student's Book of Flying High for Saudi Arabia One. This textbook is taught by Saudi TEFL teachers in Saudi public schools in the academic year 2016- 2017.

\subsection{Selecting the Level and the Textbook}

The researcher selected level ten because it is the first level in secondary school and the crucial grade of the students. The learners at this level are supposed to be exposed to all different levels and kinds of cognitive questions to foster their thinking skills before they finish all the secondary levels. Learners also should set for the Standardized Test of English Proficiency (STEP) exam before finishing secondary school. As a result, students must practice comprehension questions from the six levels of the cognitive domain. Therefore, the choice of the tenth-grade class was purposive.

Since Macmillan Education has been working in partnership with the Ministry of Education to develop the course Flying High for Saudi Arabia for grades 10-12 in government schools, the choice of this textbook under study (Flying High for Saudi Arabia One) was purposive. Also, the researcher himself has been teaching this textbook over three years and wanted to investigate the extent to which the textbook understudy focused on the comprehension Wh-questions in light of the revised Bloom's Taxonomy.

\subsection{Research Tool}

The researcher adopted a guide for the levels of questions based on the revised cognitive domain in Bloom's taxonomy. This guide included a description of the level of each question together with its sample verbs. 
Particularly, this tool was used to calculate the frequencies of cognitive levels of the wh-questions of the reading texts in the Student's Book of Flying High for Saudi Arabia One.

\subsection{The Criterion of the Analysis}

The criterion of the analysis is the proper inclusion of edition of Bloom's Taxonomy of the cognitive domain in the wh-questions following the reading texts in the Student's Book of Flying High for Saudi Arabia One.

\subsection{Unit of Analysis}

The unit of analysis for this research is all the reading texts wh-questions in the EFL textbook under analysis.

\subsection{Categories of Analysis}

The categories of analysis in this study are the six levels of the cognitive domain in the revised Bloom's Taxonomy (i.e. Remembering, Understanding, Applying, Analyzing, Evaluating, and Creating).

\subsection{Limitation of the Research}

This study has the following limitations:

1) It deals only with Flying High for Saudi Arabia One textbook which is intended for Saudi secondary school learners at proficiency level one.

2) It focuses only on the wh-questions that follow the reading texts in the book under the study.

3) It uses the revised Bloom's taxonomy.

\subsection{Definition of Related Terms}

Flying High for Saudi Arabia One-Student's Book: It contains eight units, with topics chosen to be particularly engaging for the first secondary school students in Saudi Arabia.

Wh-questions: refer to the questions which usually start with a word beginning with wh-. The wh- words are: who, what, which, where, when and why and end up with a question mark.

Reading text: in this study the reading texts are the ones included in the textbook of Flying High for Saudi Arabia One such as profile cards, articles, emails, letters, and diaries, followed by Wh-questions.

Proper inclusion: refers to the six types of the cognitive domain which are the Wh-questions following the reading texts in light of the revised Bloom's Taxonomy by Anderson et al. (2001).

\subsection{The Validity and Reliability of the Study}

The research tool used in this study is valid since it is adopted. The revised Bloom's taxonomy of the cognitive domain is a well- established tool that has been used and applied to different studies before. Concerning the reliability, the researcher used the inter-rater reliability. The analysis was repeated seven days after the first one following the same steps and procedures. Using Holsti's equation to calculate the reliability coefficient (Holsti, 1969), the researcher found that the agreement coefficient was $90 \%$ which indicates a high reliability of the analysis.

\section{Review of Related Studies}

Several studies have been carried out to analyze the cognitive level of EFL textbooks questions.

Razmjoo and Kazempourfard (2012) conducted a study to analyze all the activities of the four student's books of the interchange series based on the Bloom's Revised Taxonomy. The researchers followed a coding scheme to analyze the activities and of the student's books of the series. The findings of the study showed that all the series of EFL interchange textbooks focused only on the first three cognitive skills; remembering, understanding, and applying.

Another study conducted by Igbaria (2013) to examine the variety in the cognitive level represented by the wh-questions in the EFL textbook entitled Horizons $9^{\text {th }}$ grade in light of the Bloom's taxonomy. To collect the data, the researcher used Blooms' taxonomy as a guideline he also, collected the wh-questions of the first six units of the textbook under study. The findings of the study revealed that focused on the lower cognitive skills over the higher cognitive skills.

Additionally, Assaly and Igbaria (2014) content analyzed EFL textbook entitled Master Class for $10^{\text {th }}$ level. To collect the data, both researchers analyzed wh-questions, yes/No questions, multiple questions, complete questions, and statement and request questions based on Bloom's Taxonomy. They also classified them as low order thinking skills: knowledge, comprehension, and application and high order thinking skills: analysis, synthesis, and evaluation. The findings of the study revealed that the majority of the textbook's exercises 114 
focused on the lower order thinking skills, while only 59 questions dealt with higher order thinking skills.

A recent study was conducted by Mizbani and Chalak (2017) to analyze the oral skills questions of an EFL textbook entitled Prospect 3 based on Bloom's Revised Taxonomy. To collect the data, the researchers collected all listening and speaking skills of the textbook and classified them according to Bloom's Taxonomy. The results of the study indicated that all oral activities focused on the low level of cognitive skills; remembering, understanding, and application.

Within the same year, another study was carried out by Al-Skaf (2017) to evaluate all the activities in EFL textbooks in Syrian secondary schools according to Bloom's Taxonomy. The sample of the study included all students' books for eleventh grade in Syrian Arab Republic. To collect the date, the researcher utilized Bloom's Taxonomy as an instrument to analyze the questions. The findings revealed that all the EFL textbooks also emphasized on the low cognitive thinking skills: remembering, understanding, and application.

\subsection{Summary}

Regardless the analyzed skills and types of activities of all EFL textbooks, all the reviewed studies emphasized questions which demand low thinking skills. Therefore, the researcher conducted such study to investigate either the findings of the current study are emphasized on the lower thinking skills, or on the higher order thinking skills.

\section{Methodology and Procedures}

The data were collected in two stages. During the first stage, the researcher used a table with four columns for collecting the WH questions of the reading texts of the understudy textbook and recording them. The first column of the table included the number of the activity, the second column included the question, the third column included the cognitive level of the question, and the fourth column included the page number of the question. The total number of inclusion questions was 34 .

In the second stage, the researcher categorized all the 34 questions in light of the research tool (The revised edition of the cognitive domain of Bloom's taxonomy). After categorizing all questions, the researcher started counting the frequency of each level that each level of Bloom's taxonomy appeared in the table.

\section{Results and Discussion}

To answer the research question, the researcher analyzed all the Wh-questions following the reading texts in the Students' Book of Flying High for Saudi Arabia One. The results of the analysis are presented in the following Table which presents the level of the question, frequencies, and percentages for each level included in each learning unit of the textbook.

Table 1. Frequencies and percentages of the wh-questions following the reading texts

\begin{tabular}{|c|c|c|c|c|c|c|c|c|c|c|c|}
\hline \multirow{2}{*}{ No } & \multirow{2}{*}{ Level of question } & \multicolumn{8}{|c|}{ Units } & \multirow{2}{*}{ Frequencies } & \multirow{2}{*}{ Percentage } \\
\hline & & 1 & 2 & 3 & 4 & 5 & 6 & 7 & 8 & & \\
\hline 1 & Remembering & 16 & 1 & 0 & 3 & 0 & 1 & 0 & 4 & 25 & 73 \\
\hline 2 & Understanding & 0 & 4 & 0 & 2 & 0 & 0 & 0 & 0 & 6 & 17 \\
\hline 3 & Applying & 0 & 0 & 0 & 1 & 0 & 0 & 0 & 0 & 1 & 2.9 \\
\hline 4 & Analyzing & 0 & 0 & 0 & 1 & 0 & 1 & 0 & 0 & 2 & 5.8 \\
\hline 5 & Evaluation & 0 & 0 & 0 & 0 & 0 & 0 & 0 & 0 & 0 & 0 \\
\hline 6 & Creating & 0 & 0 & 0 & 0 & 0 & 0 & 0 & 0 & 0 & 0 \\
\hline Total & & & & & & & & & & 34 & 100 \\
\hline
\end{tabular}

The total number of the Wh-questions following all the reading texts in the Student's Book of Flying High for Saudi Arabia One is 34. The cognitive level of remembering has the most significantly highest percentage in comparison with the other cognitive levels. The second highest percentage goes for the cognitive level of understanding. Whereas, the cognitive level of analysis, as the first level of higher thinking, has the third-highest percentage. Applying, as a level of the lower order thinking, has been found only in one question. Evaluation and creation have no existence in the examined questions.

The results show that Flying High for Saudi Arabia One has failed in including or adopting the two higher thinking skills of evaluation and creating. Besides, there is a shortage in the number of applying and analyzing questions.

The textbook's questions emphasized the lower order thinking skills more than higher thinking skills. Indeed, questions of the three levels: remembering, understanding, and applying were significantly given more emphasis 
and importance than the cognitive levels of higher thinking.

According to researchers in the field of foreign language teaching/ learning, the students should be allowed to master all the cognitive level to be successful in their learning and life (Assaly \& Samdi, 2015; Igbaria, 2013; Lin, 2009; Sidek, 2010). Also, the Saudi Ministry of Education gave more emphasis and focused on the tasks and activities that demand higher thinking. The learners should be critical and creative in their abilities and thinking (Ministry of Education, Directorate of Curriculum Department, 2004).

The results of the study showed that Flying High for Saudi Arabia One textbook included reading comprehension questions that required mainly the lower level demands. Also, they showed that the cognitive levels of the Wh-questions, either the lower or the higher, were not properly included. 94\% of the questions in the textbook under analysis focused on the lower thinking skills. Such focus means that the higher thinking skills were not mainly taken as a significant focus while writing the Wh-questions following the reading texts in the textbook under analysis. Even the only inclusion of one of the cognitive level of the higher thinking is found only in two questions. Analyzing questions were relatively few in comparison with the frequency of remembering, and understanding.

Bloom et al. (1956) stated that offering lower thinking skills is the basis to move to the upper level of cognition. This is true if the textbook under analysis has a reasonable percentage of offering higher thinking skills. These skills (i.e. analyzing, evaluation, and creating), to some extent, are not given a focus or significance. The students need to be engaged in higher thinking after knowing specific information about the topic. Looking at the number of questions that demand lower thinking skills, the researcher found that the authors of the textbook under analysis were not successful in their choice of presenting and including the lower levels.

Remembering has taken the highest focus. According to the researcher, the students at this level and age need to behave and learn beyond the process of remembering. Thus, the focus should be more on understanding and applying since these cognitive levels demand the students to think and depend on their abilities and skills to answer the given questions. They need to interact with the text and negotiate the meaning. It is not a matter of recalling and finding the answers or information.

One example of remembering level can be seen in the question "where was he born?" on page 2 in unit 1 . The students are not more than recalling the information mentioned in the text. Such a question does not ask the students to activate their thinking skills. This findingis against the findings of the previous research (Assaly \& Samdi, 2015), in which all the knowledge questions following the reading comprehension texts were designed in a way that requires the learners to think and interact not just to recall information. Another example can be seen on page 12 in the same unit. A question that asks the students to recall information concerning the place where AlHajri lives. It is noted that all the remembering wh-questions that were included in the textbook under analysis are short and require a short answer as well. Even the process of remembering does not give the students the chance to remember details that need them to use their language and knowledge. They demand short and simple answers which can be easily recalled and remembered.

The researcher found that most of the remembering questions were included in the first unit of the textbook under analysis in comparisons with the other units that they did not include more than four questions of this level. According to the researcher, this may be justified that the authors of the textbook under study required the Saudi EFL learners to start this course with such easy and short wh-questions following the reading texts. Also, this would encourage and motivate the learners to participate effectively by giving more concise and proper answers. Moreover, the learners at this level still young and their first year of the secondary level, including such questions that require recalling information would make them feel more confident and able to comprehend the reading passages.

Concerning understanding level, it received the second-highest percentage in the textbook under analysis. This high percentage in comparison with other percentages given to the other levels, stresses the focus on lower thinking skills. The understanding level requires the students to access the information and emphasize the students" comprehension. Question number 6 in unit 5 is one example of the level of understanding. In this question, the students are asked to summarize in one sentence the reasons that Farasan Island has a protected status. In this question, the students are asked to use their language to reflect their comprehension and understanding. Other similar questions can be found on the same page 30 number 4 . It also asks the students to summarize in one sentence what they would do if they were members of the expedition. The other four wh-questions can be found on page number 20 .

It is noted that all the six understanding cognitive levels presented in unit two and unit 4 only. Although they are written in a way that develops the ability of the students to grasp the meaning and predict the consequences, they 
were not included properly in light of the units of the textbook under analysis. The researcher believes that such a cognitive level should be included in all the eight units and presented in pair work or group work since it allows the students to develop their thinking skills by explaining, summarizing, giving reasons, or predicting based on what they read and their communicative competence. This also makes the students activating their schemata by remembering similar situations that occurred before.

The application cognitive level received the lowest percentage compared with the other two levels of the lower order thinking. It has only one question in unit 4 . This result contradicts the results of other similar studies (Razmjoo \& Kazemporufard, 2012; Riazi \& Mosalaejad, 2010) where the application questions were frequently included. Question number 8 on page 30 in unit 4 is the only example of the application question. In this question, the students are asked to discuss how the Farasan Islands can benefit from tourism and how it could be a problem in a group. The good thing at this question is to make the students discuss how to get benefits from the Island. It also urges the students to develop their abilities concerning problem- solving which means the students' thinking skills will be developed implicitly. The teacher can write and such questions in order to motivate the students' abilities to solve problems and activate their background knowledge. Again, authors and curriculum designers should focus on this level of a cognitive domain in textbooks under analysis since the students at this level and age are able to think critically and solve a problem they may encounter in their context.

The analyzing cognitive level is the only level of the higher that is included in the wh-questions following the reading texts in the textbook under analysis. On the other hand, the questions that required the cognitive level of evaluation and creating are not included at all. This result contradicts the previous study Assaly and Samadi (2015), in which more emphasis was on questions that required higher thinking skills. Even the percentage of the presentation of the analysis level has not a good percentage in comparison with the percentage of presenting of lower thinking skills. The first example can be seen on page 30 in unit 4 which asks them "what do you think the text is trying to persuade you to do? ". Such a question activates the students' thinking skills in order to find out the correct answer. This also encourages the students to analyze the text thoroughly and examine the hidden message behind this reading text. The other example can be seen on page 52 in unit 6 which asks the students "what made fast foods different?" It also urges the students to think of the possible reasons behind making fast food different. Indeed, this question motivates the students to activate their background knowledge which is related to fast food chains in Saudi Arabia or in other countries such as KFC, Burger King, and Pizza Hut ...etc. Also, the teacher can ask many questions that urge his/ her students to think critically and focus on higher thinking skills.

Accordingly, the researcher believes that more and more questions that require higher thinking skills are needed. Also, the number of the wh- question that required lower thinking skills in the textbook under analysis is not acceptable when compared with the number of the wh-questions that require higher thinking skills.

\section{Inferences}

In light of the discussion, Flying High for Saudi Arabia One included more reading comprehension questions that require lower thinking skills than higher thinking skills. Also, the textbook authors did not successfully include cognitive levels of the reading comprehension wh-questions properly.

\section{Recommendations}

In light of the findings of this research, the researcher mentions some essential recommendations:

1) EFL Teachers need to evaluate any EFL textbook before teaching it. The textbooks should suit the learners' proficiency and cognitive level and meets the goal of the curriculum.

2) More research should be carried out in order to content analyze the other types of questions such as, yes/ no questions, tag questions and the levels of wh-questions following the reading texts in the rest of the series of the understudy textbook (Flying High for Saudi Arabia)

3) The teacher's guide and the workbook of the same textbook should be content analyzed.

\section{References}

Al-Skaf, M. (2018). An Analytic Study of the Levels of Evaluation Questions in English Courses in Syrian Secondary Schools According to Bloom's Taxonomy. A Lustath Journal for Human and Social Sciences, 222(1), 25-38.

Anderson, L., Krathwohl, D., Airasian, P., Cruikshank, K., Mayer, R., Pintrich, P., ... Wittrock, M. (2001). A Taxonomy for learning, teaching, and assessing: A revision of Bloom's Taxonomy of Educational Objectives. New York: Longman.

Assaly, I., \& Igbaria, A. (2014). A Content Analysis of the Reading and Listening Activities in the EFL Textbook 
of Master Class. Education Journal, 3(3), 24-38.

Assaly, I., \& Samdi, O. (2015). Using Bloom's Taxonomy to Evaluate the Cognitive Levels of Master Class Textbook's Questions. English Language Teaching, 8(5), 100-110. https://doi.org/10.5539/elt.v8n5p100

Berelson, B. (1952). Content analysis in communication research. Glencoe, III: Free Press.

Bloom, B., Englehart, M., Furst, E., Hill, W., \& Krathwohl, D. (1956). Taxonomy of Educational Objectives: The Classification of Educational Goals. Handbook I: Cognitive domain. New York: Longman.

Brewster, S., Davis, P., \& Rogers, M. (2013). Teacher's Book. Lebanon: Macmillan Publishers Ltd.

Holsti, O. (1969). Content Analysis for the social sciences and humanities. USA: Addison Wesley Publishing Company.

Igbaria, A. (2013). A Content analysis of the WH-questions in the EFL textbook of Horizons. International Educational Studies, 6(7), 200-224. https://doi.org/10.5539/ies.v6n7p200

Krippendorff, K. (1980). Content Analysis: An introduction to tis methodology. Newbury Park, CA: Sage.

Lin, Y. (2009). Teacher and pupil responses to a creative pedagogy-case studies of two primary classes in Taiwan (Dissertation). Retrieved from https://ore.exeter.ac.uk/repository /handle/10036/79393

Marksberry, L. (1963). Foundations of creativity. New York: Harper\& Row Publisher.

Ministry of Education, Directorate of Curriculum Department. (2004). Riyadh, Saudi Arabia: Ministry Publications.

Mizbani, M., \& Chalak, A. (2017). Analyzing Listening and Speaking Activities of Iranian EFL Textbook Prospect 3 Through Bloom's Revised Taxonomy. Advances in Language and Literary Studies, 8(3), 38-43. https://doi.org/10.7575/aiac.alls.v.8n.3p.38

Rand Reading Group. (2002). Reading form Understanding Toward an Rand D Program in Reading Comprehension Office of Education Research and Improvement. Washington. Dc: Rand Education.

Razmjoo, S., \& Kazempourfard, E. (2012). On the representation of Bloom's Revised Taxonomy in Interchange Coursebooks. The Journal of Teaching Language Skills (JTLS), 4(1), 171-204.

Riazi, A., \& Mosalanejad, N. (2010). Evaluation of learning objectives in Iranian High-School and pre-university English Textbooks using Bloom's Taxonomy. The Electronic Journal for English as a Second Language, $13(4), 1-16$.

Sidek, H. (2010). An analysis of the EFL secondary reading curriculum in Malaysia: approaches to reading preparation for higher education (Dissertation). University of Pittsburgh. Retrieved from http://d-scholarship.pitt.edu/9837/1/mohdsidekharison2017.pdf

Torrance, P. (1962). Creative thinking through school experiences. New York: Charles Scribner's Sons.

\section{Appendix A}

A Table for Collecting Wh-questions following the Reading Texts From Each Learning Unit in the Student's' Book of Flying High for Saudi Arabia One

\begin{tabular}{|c|l|c|c|}
\hline \multicolumn{2}{|c|}{ Unit 1 } & level & Page \\
\hline No & Question & 6 \\
\hline 1 & Where was he born? & & 6 \\
\hline 2 & Where did he grow up? & & 6 \\
\hline 3 & What did his father do? & 6 \\
\hline 4 & What did Mark like? & & 6 \\
\hline 5 & What happened when he was 17? & & 7 \\
\hline 6 & What did he decide to do? & & 7 \\
\hline 7 & Where did he study? & 7 \\
\hline 8 & What did he do in 1996? & & 7 \\
\hline 9 & How many children does he have? & 12 \\
\hline 10 & Where does Nasir al- Hajri live? & & 12 \\
\hline 11 & How old is he according to the report? & & \\
\hline 12 & How has he managed to stay healthy? & & \\
\hline
\end{tabular}




\begin{tabular}{|c|c|c|}
\hline 13 & What job did he do as a young man? & 12 \\
\hline 14 & What doesn't Nasir do now that he is old? & 12 \\
\hline 15 & Where does he go when he goes out? & 12 \\
\hline 16 & Why do people visit him? & 12 \\
\hline \multicolumn{3}{|c|}{ Unit 2} \\
\hline 17 & What will Faris definitely do tomorrow? & 20 \\
\hline 18 & What won't Faris do tomorrow? & 20 \\
\hline 19 & What might Faris do tomorrow? & 20 \\
\hline 20 & What will Faris probably do tomorrow? & 20 \\
\hline 21 & How does he feel at the end of the day & 20 \\
\hline \multicolumn{3}{|c|}{ Unit 3} \\
\hline 22 & What part of the text would you read if you wanted to find information about the Farasan islands? & 30 \\
\hline 23 & What awards has the foundation won? & 30 \\
\hline 24 & What do you need to have to take part in the expedition? & 30 \\
\hline 25 & Summarize in one sentence what you would do as a member of the expedition. & 30 \\
\hline 26 & Summarize in one sentence why the Farasan island have protected status. & 30 \\
\hline 27 & What do you think the text is trying to persuade you to do? & 30 \\
\hline 28 & In group, discuss how the Farasan Island can benefit from tourism and how it could be a problem. & 30 \\
\hline \multicolumn{3}{|c|}{ Unit 6} \\
\hline 29 & What made fast foods different? & 52 \\
\hline 30 & Where fast food restaurant exist now? & 52 \\
\hline \multicolumn{3}{|c|}{ Unit 8} \\
\hline 31 & When did Abdullah become the King of Saudi Arabia? & 67 \\
\hline 32 & What did he give to KAUST? & 67 \\
\hline 33 & What does King Abdullah's scholarship programme do? & 67 \\
\hline 34 & What did King Abdullah call for in $2008 ?$ & 67 \\
\hline
\end{tabular}

\section{Copyrights}

Copyright for this article is retained by the author(s), with first publication rights granted to the journal.

This is an open-access article distributed under the terms and conditions of the Creative Commons Attribution license (http://creativecommons.org/licenses/by/4.0/). 